\title{
Laparoscopic nephrectomy: Moroccan experience of 68 cases
}

\author{
Abdoulazizi Bilgo, Amine Saouli, Tarik Karmouni, Khalid El Khader, Abdellatif Koutani and \\ Ahmed Iben Attya Andalousi
}

\begin{abstract}
Background: The aim of this study was to analyze the feasibility and the safety of laparoscopic nephrectomy in the treatment of pathologies of the upper urinary tract through the experience of the Urology B department.

Methods: We have retrospectively and monocentrally selected patients who underwent laparoscopic nephrectomy from January 2017 to December 2019. The collection was carried out on archived files, based on demographic, clinical and perioperative data. The primary endpoint was the occurrence of complications and secondarily the length of the operation and the length of hospital stay. The statistical analysis was carried out using the SPSS software.
\end{abstract}

Results: A total of 68 patients were included in our series. The average age of our patients was 57.8 years. There was a slight female predominance: 39 female patients (57.4\%) for 29 male patients (42.6\%). Indications for nephrectomy were dominated by renal tumor (33.82\%) followed by lithiasis (16.17\%) and non-functioning kidney (16.17\%) at the same rank. During the study period, 31 (45.6\%) simple nephrectomy, 26 (38.2\%) total nephrectomy, 1 (1.5\%) partial nephrectomy and 10 (14.7\%) nephroureterectomy were performed in our department. In our series, the average operating time was $180 \mathrm{~min}$. Estimated blood loss averaged $321.8 \mathrm{ml}$ with extremes of a few milliliter to $1100 \mathrm{ml}$. Intraoperative complications were reported in 10 (14.7\%) patients; conversion was necessary in 6 cases (8.82\%). The postoperative follow-up was straightforward in 53 (77.94\%) patients with an average hospital stay of 3.6 days. The rate of postoperative complications according to Clavien-Dindo was 22.1\%. Histological examination of the nephrectomies carried out in our department revealed mainly chronic non-specific pyelonephritis in 24 (35.3\%) patients, followed by renal cell carcinoma in 23 (33.82\%) patients and urothelial carcinoma in 9 (13.2\%) patients.

Conclusion: Laparoscopic nephrectomy appears to be an efficient and reliable technique. This technique has led to a significant improvement in operative morbidity, mainly represented by the length of hospital stay, operating time and blood loss.

Keywords: Nephrectomy, Laparoscopy, Feasibility, Safety, Complications

\section{Background}

Since the advent of laparoscopic surgery, many procedures have been described and performed with varying success. When it comes to urology, it all started when Ralph Clayman performed the first laparoscopic nephrectomy in 1991 [1]. He had chosen the transperitoneal

*Correspondence: amine.saouli0@gmail.com

Department of Urology B, CHU Ibn Sina, Faculty of Medicine

and Pharmacy, Mohamed V University, Rabat, Morocco
(TP) route to perform a right nephrectomy, and during the same year, Ferry performed a left nephrectomy by the same route [2, 3]. In 1993, Gaur proposed the retro-peritoneal (RP) approach to perform laparoscopic nephrectomy [4]. Since then, laparoscopic nephrectomy has undergone significant development, whether performed trans or retroperitoneally, with or without robot assistance. The operative consequences of this technique remain simple, less painful, and the recovery time is shorter than open surgery. 
The aim of this study is to evaluate the feasibility of laparoscopic nephrectomy, its advantages and especially its complications through the experience of the urology B department of the Ibn Sina hospital.

\section{Methods}

We retrospectively analyzed, at the urology department, a cohort of patients who had undergone laparoscopic nephrectomy; all surgical indications taken together, over 3 years from January 2017 to December 2019, were excluded from our study patients with incomplete records.

We were particularly interested in the length of hospitalization, the duration of the operation and the postoperative complications. All patients gave their informed and free consent. Data collection was carried out on an operating sheet summarizing the clinical, biological and radiological parameters of the different patients. Statistical analysis was performed by IBM SPSS Statistics 20 software.

\section{Results}

We included in our study 68 patients including 39 women and 29 men whose median age was $57.8 \pm 14$ years (Table 1). The indications for hospitalization were based on ultrasound and abdominal-pelvic CT data. The CT scan done systematically for all patients found:

- Kidney tumor in 23 patients (33, 82\%);

- Upper urinary tract urothelial carcinoma (UUTUC) in 9 patients (13.2\%);

- Severe hydronephrosis with destroyed renal parenchyma in 27 patients (39, 7\%).

- A normal kidney in pre-transplantation in 8 cases (11.7\%).

- A compressive renal cyst in a patient.

The pre-anesthetic consultation assigned an ASA I score to nearly half of the patients (31 patients) an ASA II score to 31 other patients and an ASA III score to 6 patients.

All the patients underwent transperitoneal LN except one, who underwent a retroperitoneal approach. Fortyfour left nephrectomies (64.7\%) and 24 right nephrectomies (35.3\%) were performed, divided into:

- 31 (45.6\%) simple nephrectomy

- $26(38.2 \%)$ radical nephrectomy

- 1 (1.5\%) partial nephrectomy

- 10 (14.7\%) nephroureterectomy

The operating time is defined as the time elapsed between the incision and the skin closure. It was
Table 1 General characteristics of our population

\begin{tabular}{|c|c|}
\hline Collected characteristics & Population n (\%) \\
\hline Age (year) & $58,7 \pm 14$ \\
\hline Gender (M/F) & $29 / 39$ \\
\hline History $(n=68)$ & $(\%)$ \\
\hline HTA & $29(42,6)$ \\
\hline Diabetes & $12(17,6)$ \\
\hline Chronic renal failure & $09(13,2)$ \\
\hline Ischemic heart disease & $04(5,9)$ \\
\hline Surgery & $07(10,3)$ \\
\hline Clinical signs $(n=68)$ & $(\%)$ \\
\hline Back pain & $38(55,9)$ \\
\hline Hematuria & $20(29,4)$ \\
\hline Lucky find & $20(29,4)$ \\
\hline ASA I Score & $31(45,6)$ \\
\hline ASA II Score & $31(45,6)$ \\
\hline ASA III score & $06(08,8)$ \\
\hline Ultrasound $(n=68)$ & $(\%)$ \\
\hline UHN & $36(52,9)$ \\
\hline Renal mass & $23(33,8)$ \\
\hline Compressive renal cyst & $01(01,5)$ \\
\hline Normal kidney in pre-transplantation & $08(11,7)$ \\
\hline Uroscan $(n=68)$ & (\%) \\
\hline Kidney tumor & $23(33,8)$ \\
\hline TEVS & $09(13,2)$ \\
\hline UHN on stone & $11(16,2)$ \\
\hline UHN on junction syndrome & $03(04,4)$ \\
\hline UHN on ureteral stenosis & $02(02,9)$ \\
\hline Mute kidney & $11(16,2)$ \\
\hline Nephrectomies $(n=68)$ & (\%) \\
\hline Simple & $31(45,6)$ \\
\hline Expanded totals & $26(38,2)$ \\
\hline Partial & $01(01,5)$ \\
\hline Nephroureterectomy & $10(14,7)$ \\
\hline Histopathology $(n=68)$ & $(\%)$ \\
\hline Chronic non-specific pyelonephritis & $24(35,3)$ \\
\hline Urinary tuberculosis & $04(05,9)$ \\
\hline Urothelial carcinoma & $09(13,2)$ \\
\hline Tubulopapillary carcinoma & $03(04,4)$ \\
\hline Chromophobic carcinoma & $05(07,3)$ \\
\hline Oncocytoma & $02(02,9)$ \\
\hline Leiomyosarcoma & $01(01,5)$ \\
\hline XP 11.2 translocation carcinoma & $01(01,5)$ \\
\hline Renal cell carcinoma & $11(16,2)$ \\
\hline
\end{tabular}

$180 \pm 58.8 \mathrm{~min}$ with extremes of $(60-378 \mathrm{~min})$. Blood loss was estimated on average at $321.8 \pm 55.4 \mathrm{ml}$.

Ten patients presented intraoperative complications, 6 of which required conversion to open surgery. The 
Table 2 Postoperative complications according to the ClavienDindo classification

\begin{tabular}{lllll}
\hline $\begin{array}{l}\text { Postoperative } \\
\text { complications }\end{array}$ & $\begin{array}{l}\text { Number of } \\
\text { patients } \\
\mathbf{N}(\%)\end{array}$ & $\begin{array}{l}\text { Post-op } \\
\text { delay }\end{array}$ & Treatment & Clavien \\
\hline Infection of the & $7(10,3)$ & D3 & Local care & I \\
wall & $4(5,9)$ & D1 & Analgesics & I \\
Subcutaneous & $3(4,4)$ & D0 & Transfusion & I \\
emphysema & $1(1,5)$ & D2 & Surgical revi- & V \\
Anemia & & & sion & \\
Death & & & & \\
\hline
\end{tabular}

postoperative consequences were simple in 53 (77.94\%) patients with an average hospital stay of $3.6 \pm 1.7$ days.

Postoperative complications involved 15 patients including 7 wall infections (Clavien-Dindo 1), 4 subcutaneous emphysemas (Clavien-Dindo 1), 3 cases of anemia resulting in transfusion (Clavien-Dindo II) and 1 death. However, no respiratory complications or thromboembolic complications were observed. And the patients had a return to normal physical activities after 3 weeks (Table 2).

Anatomopathological analysis of the surgical specimens found:

- Chronic non-specific pyelonephritis in 24 (35.3\%) patients;

- Urinary tuberculosis in 4 patients;

- Urothelial carcinoma in 9 patients;

- Tubulopapillary carcinoma in 3 patients;

- Chromophobic carcinoma in 5 patients;

- Oncocytoma in 2 patients;

- Leiomyosarcoma of the renal vein in 1 patient;

- XP 11.2 translocation carcinoma in 1 patient

- Clear cell renal cell carcinoma in 11 patients

The laparoscopic approach to the kidney has become the surgical technique par excellence in the urology department in view of the exponential increase in the number of laparoscopic nephrectomies in recent years, ranging from 5 per year in 2015 to 30 procedures in 2019 (Fig. 1).

\section{Discussion}

Since the first LN performed by Ralph Clayman in 1991, the laparoscopic approach of the kidney has become the technique of choice in the surgical management of renal pathologies. It has experienced considerable growth in both material resources and the skills of practitioners, with the advent of the robot and the popularization of laparoscopic surgical technique. LN currently occupies a large place among the surgical options

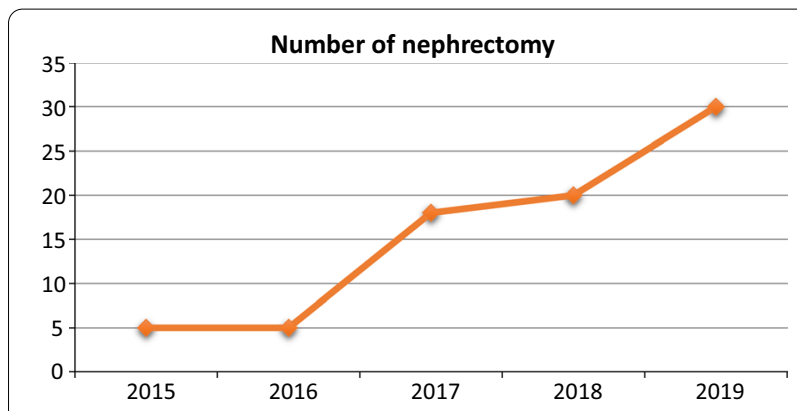

Fig. 1 Chronological evolution of laparoscopic nephrectomy in the department of urology B (HIS)

available at the urology B department, evidenced by the rate of $30 \mathrm{LN}$ per year since 2019 .

The indications for LN were based on data from the morphological assessment, including obligatorily an uroscan. The surgical option is always discussed at a service meeting, taking into account the scan results, the prognosis of the pathology in question, the patient's renal function and its comorbidities. The predominant aetiologies in our series were neoplasms (32 patients with renal tumor or UUTUC) and dumb kidneys (27 patients with a kidney destroyed either on calculus, on junction syndrome or on ureteral stenosis). The functional value of the kidney was judged both on the contrast uptake at nephronic time on the uroscanner, and on the renal scintigraphy.

Laparoscopic surgery is characterized by lengthening the operative time, but in contemporary series and that of Rozenberg et al. the mean operating time is identical to that of conventional surgery (116 min) [5]. The average duration of surgery reported in the literature ranges from 101 to $336 \mathrm{~min}$. In our series, it was in the order of $180 \pm 58.8 \mathrm{~min}$.

Blood loss in published series ranged from 0 to $828 \mathrm{ml}$. The lowest losses recorded by Oscar Schatloff et al. [6] in a retrospective study including 129 patients admitted for laparoscopic nephrectomy, and the highest by Hee Youn Kim et al. [7] in a comparative study of the retroperitoneal (34 patients) and transperitoneal (30 patients) pathways of laparoscopic radical nephrectomy for large solid renal tumors $(>7 \mathrm{~cm})$.

The conversion to open surgery is not in itself a complication; on the contrary, it is a reasoned and reasonable change of strategy which allows the patient's best interests to be kept in mind at all times. According to Keeley et al. [8], the need for conversion is more often related to the underlying disease than to the experience or ability of the operator. We totaled 6 cases of conversion due to bleeding, hepatic laceration, adhesions or colonic breach. 
The postoperative results have quite variable results, but it is difficult to make a comparison because there is no consistency in the definitions of postoperative complications. Abdominal pain and shoulder pain are frequent postoperative complications, apparently due to irritation of the peritoneum and diaphragm by carbon dioxide. They are often suppressed by minor analgesics as in our series.

Most of the authors, in their comparative series, identify minor complications, designating those requiring medical treatment and/or simple monitoring, and major complications, which were defined as those requiring hospitalization in intensive care units, reoperation or potentially fatal [9]. In our series, we noted 11 ClavienDindo I complications, 3 Clavien-Dindo II complications and 1 death. Histological examination of the operative specimen confirmed tumors R0 excision during these different LN.

In terms of downsides, the RP approach has reduced workspace, limited landmarks, and in the case of a dorsal renal tumor, the renal vessels are spotted. In contrast, the TP approach presents a risk of damage to adjacent abdominal organs, requires bowel mobilization, difficulty with renal artery procedures and a history of abdominal surgery [10].

\section{Conclusion}

Laparoscopic nephrectomy is a surgical technique with very satisfactory results for both practitioners and patients, with respect for carcinological rules. It remains preferred in our center, compared to open nephrectomy when the indication is suitable. It allowed a significant improvement in operative morbidity, mainly represented by the length of hospital stay, the operative time and blood loss.

\section{Abbreviations}

TP: Transperitoneal; RP: Retroperitoneal; LN: Laparoscopic nephrectomy; ASA: American Society of Anesthesia; UT: Urothelial tumor.

\section{Acknowledgements}

Not applicable.

\section{Authors' contributions}

$A S$ and $A B$ analyzed and interpreted the patient data regarding the subject and were a major contributor in writing the manuscript. TK, KE, AK and AIAA read and approved the final manuscript. All authors read and approved the final manuscript.

Funding

No funding

Availability of data and materials

Not applicable.

\section{Declarations}

\section{Ethics approval and consent to participate}

The ethics committee of the Faculty of Medicine of Rabat has given us its agreement. Informed and verbal consent to participate in the study was provided by our patients. The reference number is not applicable.

\section{Consent for publication}

Not Applicable.

\section{Competing interests}

The authors declare that they have no conflicts of interest in connection with this article.

Received: 27 February 2021 Accepted: 10 May 2021

Published online: 18 May 2021

\section{References}

1. Kapoor A (2014) Linvasion robotique au Canada. Can Urol Assoc J 8:e466-e467

2. Clayman RV, Kavoussi LR, Soper NJ, Dierks SM, Meretyk S, Darcy MD et al (2017) Laparoscopic nephrectomy: initial case report. J Urol 197:S182-S186

3. Ferry N, Sala JJ, Gehin C, Chevreau C, Valet V (1991) Laparoscopic nephrectomy. Progres Urol 1:918-919

4. Gaur DD, Agarwal DK, Purohit KC (1993) Retroperitoneal laparoscopic nephrectomy: initial case report. J Urol 149:103-105

5. Rozenberg H, Bruyere F, Abdelkader T, Husset A, Hamoura H (1999) Transperitoneal laparoscopic nephrectomy. Progres Urol 9:1034-1038

6. Schatloff O, Nadu A, Lindner U, Ramon J. Simplifying laparoscopic nephrectomy: the inferior approach with en bloc stapling of the renal hilum. JSLS. 2014;18.

7. Kim HY, Lee DS, Yoo JM, Lee JH, Lee SJ (2017) Retroperitoneal laparoscopic radical nephrectomy for large $(>7 \mathrm{~cm})$ solid renal tumors: comparison of perioperative outcomes with the transperitoneal approach. $J$ Laparoendosc Adv Surg Tech A 27:393-397

8. Keeley FX, Tolley DA (1998) A review of our first 100 cases of laparoscopic nephrectomy: defining risk factors for complications. Br J Urol 82:615-618

9. Donat SM (2007) Standards for surgical complication reporting in urologic oncology: time for a change. Urology 69:221-225

10. Taue R, Izaki H, Koizumi T, Kishimoto T, Oka N, Fukumori T et al (2009) Transperitoneal versus retroperitoneal laparoscopic radical nephrectomy: a comparative study. Int J Urol 16:263-267 